Wardle J, Huebner Y, Blythe PT, Gibbon J. The provision of public recharging infrastructure for Electric Vehicles in North East England - is there life after subsidies? In: International Conference on Sustainable Infrastructure (ICSI). 1721 November 2014, Long Beach, California, USA: ASCE.

DOI link

http://dx.doi.org/10.1061/9780784478745.032

ePrints link

http://eprint.ncl.ac.uk/208928

Date deposited

$04 / 04 / 2018$

Copyright

This material may be downloaded for personal use only. Any other use requires prior permission of the American Society of Civil Engineers. This material may be found at http://dx.doi.org/10.1061/9780784478745.032 


\title{
The provision of public recharging infrastructure for Electric Vehicles in North East England - is there life after subsidies?
}

\author{
Josey Wardle ${ }^{1,3}$, Dr Yvonne Hübner ${ }^{1}$, Prof Phil Blythe ${ }^{1}$, Dr Jane Gibbon ${ }^{2}$
}

\author{
${ }^{1}$ Newcastle University, Transport Operations Research Group (TORG), Civil \\ Engineering and Geosciences, Newcastle Upon Tyne, NE1 7RU, UK, email: \\ j.wardle3@newcastle.ac.uk \\ ${ }^{2}$ Newcastle University Business School, 5 Barrack Road, Newcastle upon Tyne, NE1 \\ 4SE, UK \\ ${ }^{3}$ Zero Carbon Futures, SASMI, Washington Road, Sunderland, SR5 3HE, UK
}

\section{ABSTRACT}

Since 2010 over 1,100 electric vehicle (EV) charge points have been installed in North East England (NE) through the UK government subsidised Plugged in Places scheme. In parallel, over 65,000 EV journeys were studied through the Switch-EV trial. Public subsidies covering the operation of EV recharging infrastructure are now coming to an end in the region, which is likely to affect EV drivers recharging behaviour. It is however unlikely that the introduction of fees for recharging at a level which EV drivers are willing to pay will enable infrastructure owners to recoup their costs using conventional business models. Therefore making the financial case for the provision of public recharging infrastructure is still difficult. A social and environmental accounting framework may provide crucial information to enable organisations to understand the wider value provided by recharging infrastructure and its services, thereby opening up alternative business models. This paper gives an overview of the findings from these two projects and comments on the early changes observed as a result of the reduction in subsidies.

\section{BACKGROUND}

North East England (NE) is at the forefront of low carbon vehicle development, with Nissan manufacturing both the Nissan LEAF and Lithium-ion batteries at its Sunderland plant. Since 2010, the region has installed a comprehensive recharging infrastructure in parallel with a number of EV trials, and has become a major hub for vehicle and battery research and development, manufacturing, and training facilities throughout the EV supply chain.

The EV recharging infrastructure has been installed through Plugged in Places (PIP), a government funded programme operated by the Office for Low Emission Vehicles (OLEV) which has awarded funding to 8 areas within the UK in order to establish EV recharging infrastructure to seed the uptake of low carbon vehicles. The aims of the programme are to feedback the experience gained by creating and operating EV recharging infrastructure into future policy decisions at both regional and national 
levels. This includes the development of standards, evaluation of technologies, harmonisation of local incentives, understanding users' behaviour and its impact upon the infrastructure.

The second key element of the NE's electric vehicle activity involved 44 EVs trialled under the Technology Strategy Board's (TSB) Ultra-low carbon vehicle demonstrator (ULCVD) programme. The Switch EV trial brought together a consortium of vehicle manufacturers, data collection experts and project managers to deliver 44 new and innovative full- electric production vehicles onto NE roads.

\section{METHODOLOGY}

\subsection{The NE PIP project.}

North East England's Plugged in Places (NE PIP) project, created an integrated recharging network for EVs spanning a region of 8,600 $\mathrm{km}^{2}$ between April 2010 and June 2013. This recharging infrastructure enables EV journeys to become feasible across neighbouring regions in the UK, Scotland and Europe. The project installed 1,138 charge points in public places, workplaces and in the homes of EV drivers across the region. The estate includes a combination of 3, 7 and $22 \mathrm{~kW}$ AC charge points, and the NE was the first UK area to create a regional network of $50 \mathrm{~kW} \mathrm{DC}$ rapid charge points which enable EVs to be recharged to $80 \%$ in just 30 minutes. 12 rapid chargers were installed by the NE PIP project at key staging points across the region.

Potential hosts were attracted to have charge points installed on their property by various levels of grant incentives covering equipment and installation costs. Charge points have consequently been installed in locations in accordance with demand from interested hosts. In exchange for this grant funding, each host provided free electricity and free parking to EV drivers during the three year trial period, which ended in June 2013. The charge point hosts now own the NE's EV recharging infrastructure which forms the NE recharging estate. All publically accessible charge points were operated by a single network operator, Charge Your Car (CYC)[1]. CYC was funded to provide access to the entire NE recharging estate, as well as to provide customer service and charge point information via a live availability map on a dedicated website. EV drivers joined the NE PIP's CYC membership scheme at a cost of $£ 100$ per year or $£ 10$ per month, in order to receive free electricity and parking whilst recharging, access to the website to plan their journeys and their own recharging records. In addition to this public and workplace infrastructure, the project also installed over 400 domestic chargers with captive cables for EV drivers in the region to use in their own home environment.

\subsection{Data Collection from charge points}

CYC members were issued with their own personal radio-frequency identification (RFID) card which had a unique tag identifier attached to it, enabling them to access all makes of public and workplace EV charge points across the region. All charge points had their own unique identifying code denoting: 
- the charge point type (power delivery rating, single or double outlet),

- location type (Public $=$ on street, in a public or commercial car park, Workplace, Rapid)

- location identification number (latitude \& longitude coordinates).

All public and workplace charge point activities were then recorded by the Back Office system managing the charge point network for the project, creating a charge point management system (CPMS). For each charging activity, the tag id, the transaction start and end date and time and the energy drawn were then transmitted via the GSM network to the Back Office operating the CPMS. Both charge point hosts and EV drivers had access to their own charging data and history via a Members Portal within the CPMS.

\subsection{Switch-EV trial}

The Switch-EV trial ran from November 2010 until May 2013. The vehicles were fitted with data loggers that provided a range of driving and vehicle performance data, GPS and a time stamp. Selected data points were collected and analysed at Newcastle University and in parallel, driver attitudes towards driving and recharging EVs were gathered through questionnaires and focus groups. The two sets of data were then correlated to explore trends, changes in driving and recharging behaviour, general attitudes towards EVs, recharging and key issues such as cost. Most of the Switch EV drivers were also members of the CYC scheme and used the recharging infrastructure created by the NE PIP project.

Over the course of the Switch EV project, 192 participants provided answers to a pre-trial questionnaire and 101 provided answers to the post-trial questionnaire. In addition, 60 participants attended 12 focus groups; 12 individual exit interviews and 10 pre-trial interviews were conducted in order to understand drivers' attitudes towards EVs and their recharging infrastructure. Quotes from the drivers that have been reproduced from their questionnaire reposes or captured from the oral record of the focus groups are presented in quotes: “...”.

\subsection{Data Collection from EVs}

The Switch-EV project collected hard data on the vehicles derived from the controller area network (CAN) bus of the vehicle and transmitted to a secure database through wirelessly enabled data loggers fitted within the vehicle. Those data were overlaid with GPS and time stamps derived from an additional logging unit in the vehicle. Data collected included:

- Time/date - start, end and duration of events ( trips and recharging events)

- Distance travelled

- Energy used per trip

- Energy transferred per recharge

- Recharging location (home, work, public charging infrastructure)

\section{RESULTS}

\subsection{NE PIP project - public recharging results}


The composition of the 737 public and workplace charge points in NE PIP estate is illustrated in Figure 1, broken down into three location categories - Workplace, Public and rapid chargers. Public chargers were then subdivided into On-street, Publicly owned car parks and Commercially owned car park locations for further analysis.

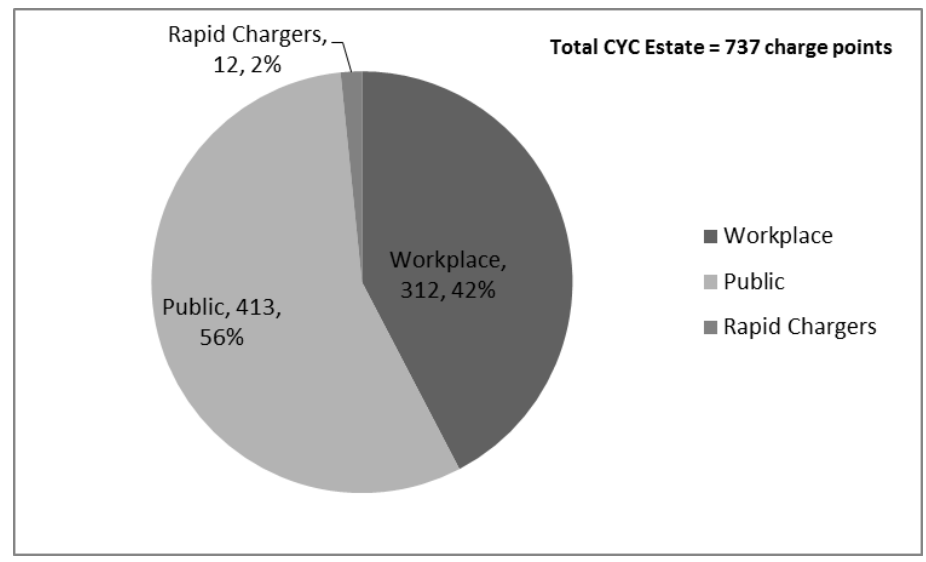

Figure 1 NE PIP Estate charge point composition by location type, June 2013.

120 hosts own the public and workplace charge points making up the NE PIP estate. However, only 17 of these hosts own more than 10 charge points each, totalling $61 \%$ of the estate. The majority ( $71 \%$ ) of NE hosts own 2 or less charge points. The main hosts are the 12 Local Authorities in the region who together own a total of $48 \%$ of the total estate. The balance of 401 charge points consists of domestic charging units installed in the homes of EV drivers in the region.

The estate of Public, Workplace and Rapid chargers has delivered over 43,000 recharging transactions and over $311 \mathrm{MWh}$ of energy to EV drivers up to the end of 2013. The proportion of transactions broken down by location category is shown in Figure 2, and the energy delivered is displayed in Figure 3.

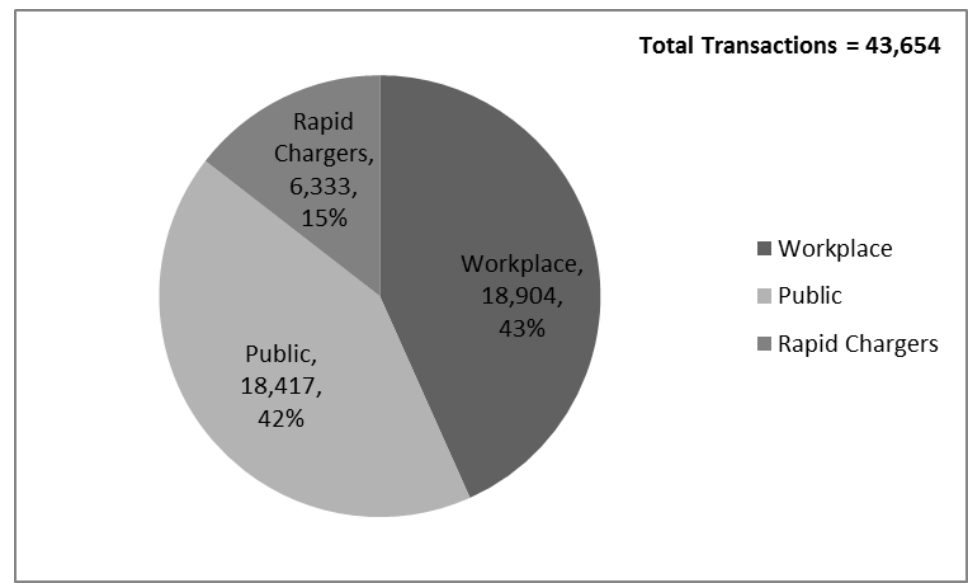

Figure 2 Recharging Transactions delivered. 


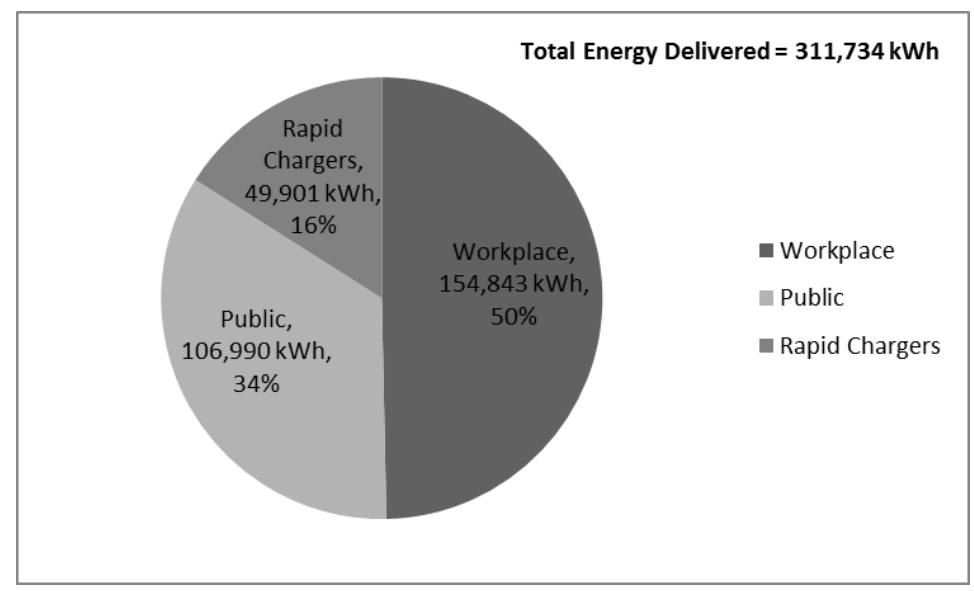

Figure 3 Energy delivered to end of 2013.

The $50 \mathrm{~kW}$ DC Rapid Chargers delivered a much higher proportion of the transactions (15\%) and total energy provided by the estate $(16 \%)$ than their composition proportion suggests $(2 \%)$. Conversely, the public $3 \mathrm{~kW}$ and $7 \mathrm{~kW}$ charge points in publicly and commercially owned car parks and on streets delivered a lower proportion of the total energy (a combined 34\%) compared to their composition (a combined 42\%).

One of the reasons for this is the difference in usage patterns throughout the week as shown in Figure 4. Recharging events at the workplace chargers fell markedly at the weekend, similar to those of public charge points. However the number of recharging events on the rapid chargers remained relatively constant throughout the week.

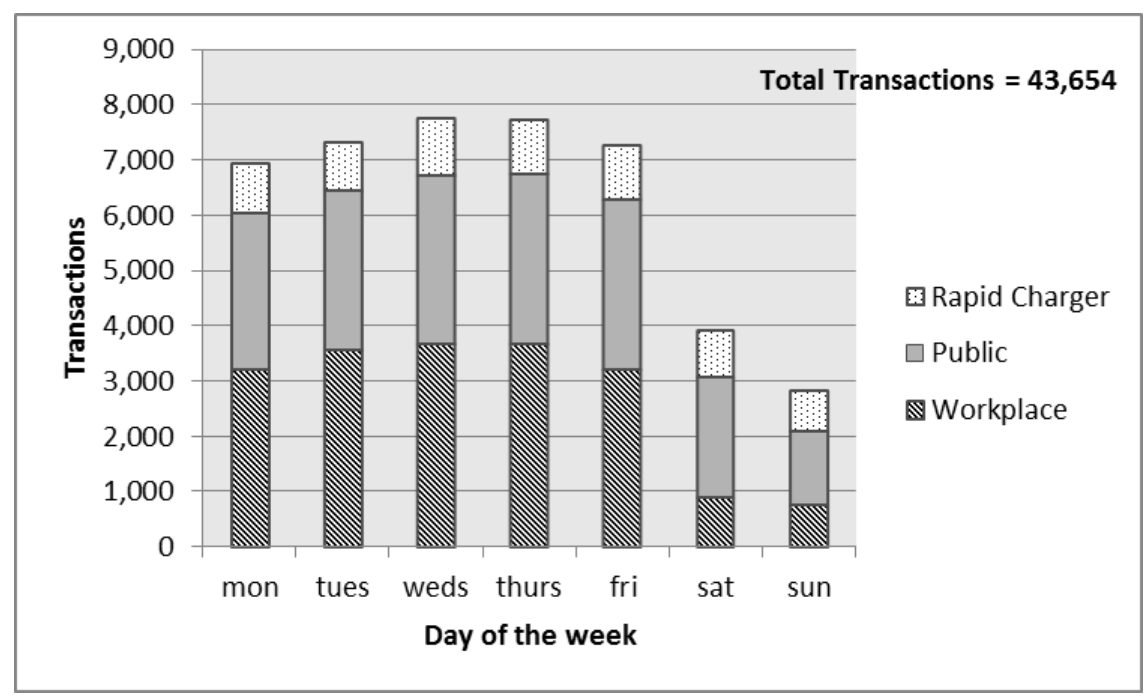

Figure 4 Number of recharging events by day of the week.

Secondly, the energy transferred per charge event differs between the different charge point location types. As shown in Table 1 below. 


\begin{tabular}{|l|r|}
\hline Charge Point Location type & kWh \\
\hline Workplace & 8.19 \\
\hline Publicly owned carpark & 5.93 \\
\hline Commercially owned carpark & 5.91 \\
\hline On Street & 5.10 \\
\hline Rapid Charger & 7.88 \\
\hline
\end{tabular}

Table 1 Average energy delivered per transaction

There has also been a large increase in the number of transactions taking place during 2013 as illustrated in Figure 5.

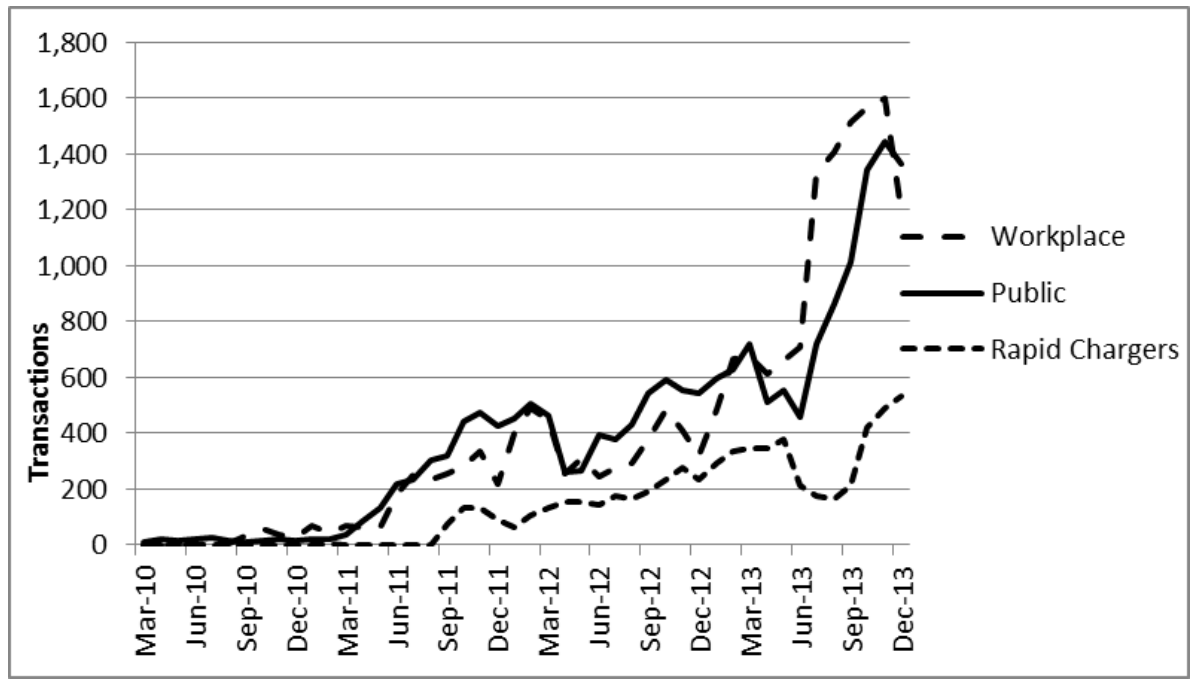

Figure 5 Growth in Transactions

This increase in recharging transactions coincides with a large increase in the number of EVs in use in NE, which rose from just over 100 in 2012 to over 450 by June 2013. These figures were collated from drivers applying for domestic chargers through the NE PIP project, rather than from UK national registration statistics which are influenced by national fleet and lease office addresses rather than EV driver addresses.

This increase also coincides with the end of the NE PIP project and therefore the end of its subsidy for charge point operation.

The changes in use of the NE's recharging infrastructure will continue to be studied over the next 3 years, alongside an analysis of how the use of Domestic chargers affects the demand for public recharging in the region.

\subsection{Switch-EV - attitudes towards recharging}

The Switch-EV trial saw 44 full EVs cover over 400,000 miles across the NE between March 2010 and May 2013, which account for over 90,000 journeys and over 19,000 recharging events. 
Analysis of the trial data shows that $30 \%$ of charge events in the NE took place at public charge posts, primarily during peak electricity demand hours. Further analysis of the charge events revealed that nearly $20 \%$ of EV users seemed to be using the public recharging infrastructure as their primary means of recharging. In the posttrial questionnaire and focus groups, participants identified the location, common availability and free parking incentives as reasons for this behaviour.

One EV driver confirmed this in the focus groups: "We're lucky enough to have some public infrastructure right beside where we work so that we just plug it in really while we work and then take it home ... I've never charged it on anything else apart from public infrastructure so that's been the source for all our charging - or all my charging anyway." Another driver explained why they used public recharging infrastructure mostly to charge the vehicle: "I've been parking [at a charge post in the city centre] which has been a godsend. My office is 25 feet away, and parking is free; so this car has actually paid us. We have saved money by renting the car". Other drivers said that they enjoyed the convenience of parking at the EV charging bays: "I take the EV not because I'm going to get a free parking space. It's just convenience. There are lots of them [charging posts], they're in good locations and I know I can get one and it's convenience rather than cost." Not surprisingly, most drivers therefore said that the access to public standard chargers and public rapid chargers was either very important or quite important.

Yet, as shown in Figure 6, respondents identified concerns about recharging as two of the key barriers to the uptake of electric EVs; the time required for recharging and availability of recharging infrastructure.

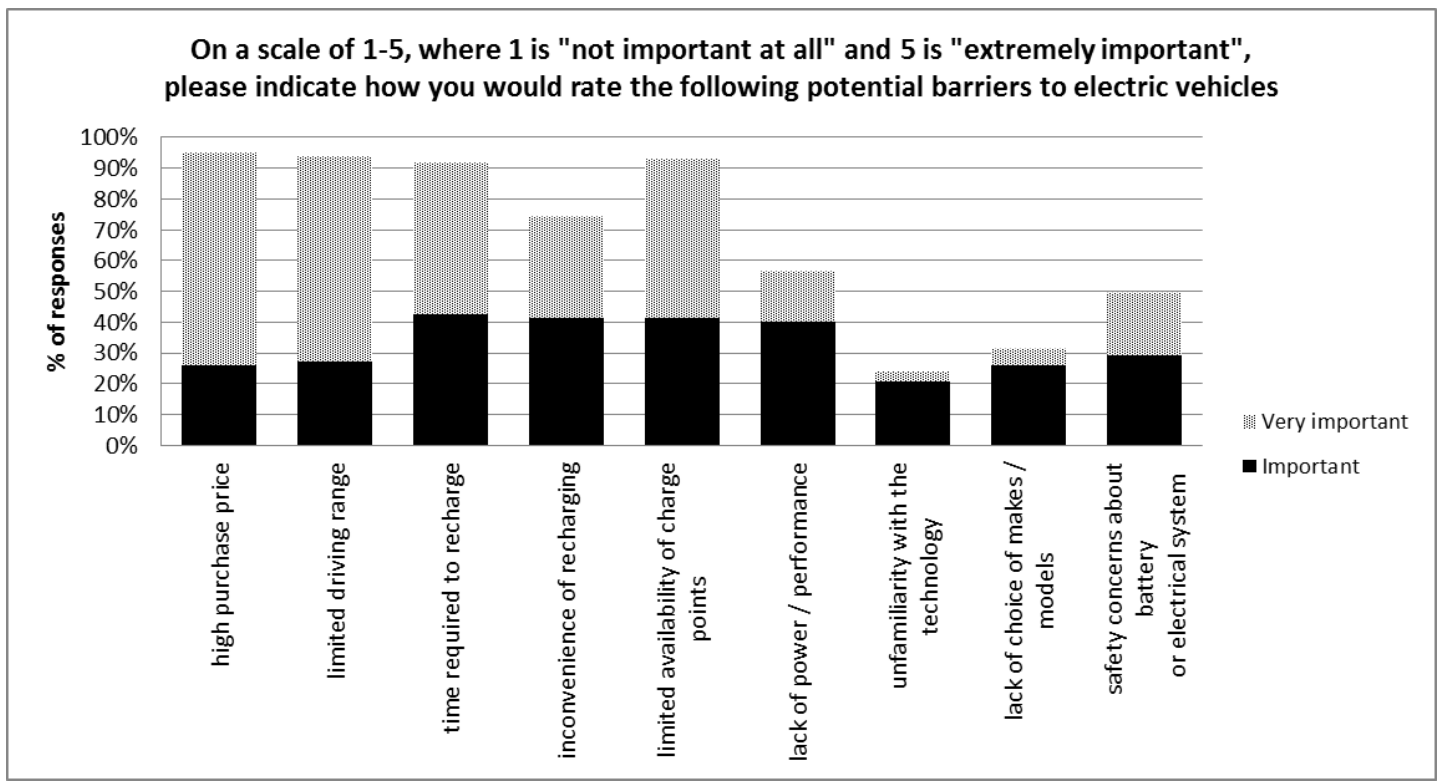

Figure 6 - Switch EV drivers perceived barriers to the uptake of EVs.

\subsection{Findings from these projects}

The analysis of data from these two projects shows that; 
- Almost half (48\%) of the NE estate of charge points is owned by organisations with social objectives, Local Authorities.

- A relatively small proportion of NE Hosts (14\%) own the majority of the NE estate (61\%), so the likelihood of achieving a single business model appropriate for all is very low.

- Rapid chargers deliver a disproportionate amount of transactions and power in relation to the number of charge points within the estate

- Public 3 and $7 \mathrm{~kW}$ charge points deliver a lower average power per transaction than workplace based equivalents.

- During the Switch-EV trial only 30\% of charging events took place on public charge points.

- The patterns of recharging behaviour observed were in part impacted by external influences, such as free parking. Therefore further analysis of EV charging behaviour is now being performed over the next 3 years whilst recharging schemes are changing in the region.

\section{Subsidies for $\mathrm{EV}$ recharging in the UK}

The early provision of EV recharging infrastructure in the UK has been heavily subsidised by UK government, local authorities and private companies as part of sustainable transport and emission reduction plans. The Plugged in Places programme is the UK's main subsidy tool to promote the provision of EV recharging infrastructure. In 2011 the UK government, through OLEV, issued its first low emission vehicle strategy entitled 'Making the Connection'[2], which set out a framework for creating a recharging infrastructure for plug-in vehicles. The Plugged-in Places programme (PIP)[3] was created to address this challenge, alongside a range of vehicle incentives. These include the Plug-in $\mathrm{Car}(\mathrm{PiCG})[4]$ and Van Grants(PiVG)[5], Plugged-in Fleets initiative[6] and Low Carbon Vehicle Public Procurement programme(LCVPP)[7], which are all designed to encourage the up-take of low-carbon vehicles in the UK.

With the end of the funded operation of the NE charge points by the NE PIP project, the public charge point estate must now become self-sustaining. Charge point owners can now therefore charge EV drivers a fee for the use of their EV charging facilities, as a way of recouping their up-front capital investment and on-going operating costs.

Since the NE PIP project no longer pays for the operation of the NE's recharging estate, charge point owners must engage a Network Operator to provide the necessary charge point management services (access, administration of fees, customer service, fault reporting etc). Many, but not all, of the charge points installed through the NE PIP project are now operated by CYC on a commercial basis. However, few of the owners of these charge points have yet chosen to charge a fee to EV drivers. Therefore, most NE charge point owners are continuing to provide a subsidy to EV drivers, as a way of attracting EV drivers to their facilities, whether employees or members of the public, in line with their sustainable transport plans. 
Other associated financial incentives have also continued in the region, such as the offer of free parking. All 12 Local Authorities in NE now provide public charge points as a result of the NE PIP project, and in some cases they have incurred large losses in parking revenue as a result. Increasing financial pressures have also been placed on Local Authorities by UK government and how this will affect social provision such as recharging infrastructure is yet to be established.

Workplace hosts are also likely to retain the free electricity offer for their employees as long as the relevant tax incentives are maintained and demand does not result in excessive electricity costs. However, this situation is likely to change in the future if the UK Government's approach to employee benefits in kind changes or if demand by EV drivers makes electricity costs a problem to employers.

\section{Business Models for EV recharging in public locations}

Currently there is no feasible, purely economic business model for the provision of public recharging infrastructure in the NE.

The current demand for public recharging transactions from EV drivers is not high enough to fully cover the economic costs of capital, installation, operation and maintenance. The actual uptake of EVs and therefore demand for recharging transactions has been lower than the predictions made in 2010, affecting the early business models envisaged for on-going operation and increasing provision. The consequence is that $\mathrm{NE}$ charge point owners are continuing to financially support the costs of operation of recharging infrastructure and cannot yet foresee an acceptable conventional business model.

\subsection{The charge point owner's perspective}

The charge point owner is now at the centre of a system of infrastructure which is seen as essential by many stakeholders such as government, environmental bodies and EV drivers, and they are expected to at least maintain the current level of supply. However, the expectations and assumptions upon which NE hosts made the decision to adopt charge points, have not materialised.

NE charge point owners are a diverse group of organisations who have decided to provide recharging infrastructure for a variety of political, economic, social and environmental reasons. Peer pressure is also a relevant factor in the region because of the high profile role the NE has played in low carbon vehicle development to date.

The Climate Change Act[8] is driving the implementation of sustainable transport solutions in the UK in order to reduce domestic greenhouse gas emissions. Local Authorities (LA) are therefore being encouraged by political motivations to provide appropriate services, such as EV recharging infrastructure. This represents a model of provision for social good, as opposed to the likely economic motivations of a private business. LAs may have three target audiences in which the provision of recharging infrastructure should encourage low carbon vehicle uptake; the general 
public, its own employees, and its own fleet. Private Businesses on the other hand would be targeting only their employees and own fleets. There is also a third category of NE host such as Universities which have some social and environmental targets leading them to offer recharging services to visitors as well as employees, but not to the general public.

However, the customers wishing to use these services, EV drivers, may have very different demands to those assumed by the charge point hosts.

\subsection{The EV driver's perspective}

EV drivers' demands for public recharging infrastructure are based on cost, ease of use and location. The additional services provided such as free parking have been a key determinant in NE charge point usage to date. The available capacity and reliability of charge points will also become increasingly important as EV volumes increase and in certain locations with dense EV populations this has already become a problem. An increased provision of rapid charge points would help resolve this problem but this incurs high up-front costs and higher electricity costs as it encourages greater use.

\subsection{The role of subsidies}

The NE's early-to-market EV recharging estate was created and operated under public subsidy, in order to seed the marketplace for further EV and recharging equipment adoption. The availability of NE PIP grant funding towards purchase and installation costs heavily influenced hosts decisions to adopt charge points. These grants have now ended so one hypothesis is that provision will not increase further without new government subsidies being introduced. The NE PIP project also paid all system operating costs until June 2013, so charge point owners were therefore shielded from the true costs of operation. The result is that NE charge point owners have adopted recharging infrastructure without being fully aware of the costs of operation.

As public subsidies decline, the infrastructure owners must find other ways to cover the on-going costs of operation and to recover the capital investments made, in order to provide a continuing service to EV drivers.

\subsection{The role of fees for $\mathrm{EV}$ recharging}

As charge point owners are increasingly exposed to real operating costs they will also become aware of the new commercial opportunities available to them, such as fees, marketing and the provision of associated services. The introduction of fees for EV recharging is likely to affect the behaviour of EV drivers in terms of their recharging habits (time, location, duration etc.), willingness to pay, journey characteristics and potentially their overall EV usage. These behavioural changes will, in turn, affect the owners of recharging equipment and the businesses operating this equipment in recharging networks (Network Operators).

Increased understanding of the operating costs is likely to drive assessments concerning fees and further recharging provision in different directions to those taken 
against the backdrop of public subsidy. Type, quantity and location of recharging equipment are all key determinants in this business model. Therefore studies of comparative usage data from different types of recharging equipment and charge point location types should be used to inform future fee structures.

\subsection{The way forward - a broader measurement model ?}

NE charge point owners are now faced with five elements influencing the business model for operating their recharging infrastructure; Charge point features, EV features, EV drivers' requirements, charge point technology and recharging technology. Each of these areas contains unknown factors and therefore requires predictions based on market intelligence to date. Many charge point owners do not have the capacity or business need to carry out this in depth work.

NE charge point owners also have varying reasons for providing recharging infrastructure, including political, social and environmental objectives many of which cannot be measured in purely economic terms.

There is therefore the potential for a social and environmental accounting model to be developed which will provide an alternative accounting framework for the provision of public recharging infrastructure. A social account with a measure of social return on investment would enable an organisation to assess and report its impact on society and the environment, alongside its economic measures. A flexible framework could be used to collect, analyse and interpret quantitative and qualitative data resulting from the provision of recharging infrastructure. Use of such a framework would enable charge point owners to understand and evaluate the wider value provided by recharging infrastructure and its services, and to value how it affects the people, environment and resources they are responsible for. Follow-on work will be carried out by the authors to build and assess such a framework. An analysis of charge point owners' attitudes towards their recharging infrastructure will be performed, in parallel with the authors' continuing longitudinal study of the usage of NE charge points.

\section{CONCLUSIONS}

The provision of EV recharging infrastructure in the NE and the UK is important to both government and EV drivers. Therefore either a sustainable business model is required to enable charge point owners to continue provision, or subsidies must continue. A sustainable business model is likely to have to contain social, environmental and economic elements, for which an alternative method of accounting such as a social and environmental framework may be suited.

\section{ACKNOWLEDGEMENTS}

The authors gratefully acknowledge the funding support of the UK's Engineering \& Physical Sciences Research Council and the Economic \& Social Research Council 
funding of iBUILD (Infrastructure BUsiness models, valuation and Innovation for Local Delivery) - EP/K012398/1. (http://research.ncl.ac.uk/ibuild/)

\section{REFERENCES}

1. Charge Your Car Limited. Available from: http://chargeyourcar.org.uk.

2. Office for Low Emmission Vehicles, Making The Connection, the Plug-in Vehicle Infrastructure Strategy, OLEV, Editor June 2011: London.

3. Office for Low Emission Vehicles. Plugged in Places. 2010; Available from: https://www.gov.uk/government/publications/plugged-in-places.

4. $\quad$ Office for Low Emission Vehicles, Plug-in Car Grant, 2011: https://www.gov.uk/government/publications/plug-in-car-grant.

5. Office for Low Emission Vehicles, Plug-in Van Grant, 2012: https://www.gov.uk/government/publications/plug-in-van-grant.

6. Energy Savings Trust. Plugged in Fleets Inititative. 2013; Available from: http://www.energysavingtrust.org.uk/Organisations/Transport/Products-andservices/Fleet-advice/Plugged-in-Fleets-Initiative-100.

7. Office for Low Emission Vehicles. Low Carbon Vehicle Public Procurement 2011; Available from: https://www.gov.uk/government/publications/the-lowcarbon-vehicle-public-procurement-programme-support-for-low-carbon-vans.

8. Department of Energy and Climate Change, Climate Change Act 2008, DECC, Editor: http://www.legislation.gov.uk/ukpga/2008/27/pdfs/ukpga_20080027_en.pdf. 